\title{
The Bariatric-Metabolic Physician's Role in Managing Clinically Severe Obesity
}

\author{
Claudia Coelho $^{1}$ (D) James Crane ${ }^{1} \cdot$ Rachel Agius $^{1,2} \cdot$ Barbara McGowan $^{1,3}$ \\ Accepted: 9 April 2021 / Published online: 8 May 2021 \\ (C) The Author(s), under exclusive licence to Springer Science+Business Media, LLC, part of Springer Nature 2021
}

\begin{abstract}
Purpose of Review The aim of this review is to outline the obesity physician's role in managing patients with severe obesity with a particular emphasis on bariatric surgery candidates.

Recent Findings Obesity is a chronic, relapsing and progressive disease. Scoring systems that evaluate the severity of obesity based on the clinical assessment, rather than the Body Mass Index, are a valuable tool. The clinical assessment should explore the underlying contributors for weight gain and screen for obesity-related complications. Bariatric surgery remains the most effective management approach for severe and complex obesity. Nevertheless, pharmacotherapy and other non-surgical approaches play an important role.

Summary The bariatric-metabolic physician's role is paramount in delivering effective care to patients with obesity. The multiple complications of patients with clinically severe obesity highlight the complexity of their management and reinforce the need for adequate assessment and long-term follow-up to ensure optimal clinical outcomes.
\end{abstract}

Keywords Bariatric $\cdot$ Physician $\cdot$ Clinically severe $\cdot$ Obesity $\cdot$ Management

\section{Introduction}

The global prevalence of obesity is rising. According to the World Health Organization, over 650 million people worldwide live with obesity [1]. Since 1980, the prevalence of obesity has doubled in more than 70 countries [2]. Furthermore, severe obesity is increasing [3], and no nation has yet had significant success in reducing obesity rates [4]. Obesity substantially increases the risk of complications, such as type 2 diabetes mellitus (T2DM), cardiovascular disease, obstructive sleep apnoea (OSA) and cancer [5]. It is usually a chronic, relapsing and progressive disease that requires long-term

Health Services and Programs (R Welbourn and C Borg, Section Editors)

This article is part of the Topical Collection on Health Services and Programs

Barbara McGowan

barbara.mcgowan@gstt.nhs.uk

1 Department of Diabetes and Endocrinology, Guy's and St Thomas' NHS Foundation Trust, London, UK

2 Diabetes and Endocrine Centre, Mater Dei Hospital, Msida, Malta

3 Diabetes and Nutritional Sciences, King's College London, London, UK management [6•]. Therefore, there is a need for physicians with adequate knowledge of obesity epidemiology, aetiologies, mechanisms, obesity-related complications and treatment approaches. Several guidelines from different international organisations have been published in recent years elucidating best practices in the development of a comprehensive obesity management plan $[7,8 \bullet \bullet, 9,10]$. This article aims to define clinically severe obesity and outline our role as bariatric-metabolic physicians in assessing and managing adults with clinically severe obesity in clinical practice.

\section{Defining Clinically Severe Obesity}

Clinically severe obesity is commonly defined as body mass index $(\mathrm{BMI}) \geq 40 \mathrm{~kg} / \mathrm{m}^{2}$ or $\geq 35 \mathrm{~kg} / \mathrm{m}^{2}$ with obesity-related complications. Although BMI is a universally accepted anthropometric measure, there are caveats for its use. It overestimates adiposity in people with significant lean body mass and does not inform on the distribution of adipose tissue [11]. Other common measures include waist circumference, waisthip ratio and waist-height ratio. Indices involving waist circumference infer visceral adiposity and, therefore, are markers for increased cardiometabolic risk [12]. However, these may 
be technically difficult to measure and standardise. Further tools have been used to provide information about the content and distribution of adipose tissue, such as bioimpedance, quantitative magnetic resonance, air-displacement plethysmography, dual-energy x-ray absorptiometry and magnetic resonance imaging [13]. However, none of these anthropometric measures or investigations reveals the extent and severity of complications or provides a rational framework for decision-making in clinical settings [14]. To address these issues, more holistic staging systems have been developed. In our practice, we assess obesity severity with the King's Obesity Staging Criteria (KOSC). The KOSC categorizes a person's health according to their physical, psychological, socioeconomic and functional statuses, as shown in Table 1. It is a validated staging score that can be used to quantify the impact of interventions and has shown the benefit of bariatric surgery [15]. The KOSC ensures that all health domains are covered in a systematic manner, and it is a practical way to summarise the patient's current health status. It standardises the assessment of obesity-related complications such as sleepdisordered breathing, cardiovascular disease, diabetes, musculoskeletal disease, reproductive health, mental health, gastrooesophageal reflux disease, kidney and liver disease. If the patient scores highly on several domains, specialist input may be required and more intensive weight loss strategies such as bariatric surgery should be employed.

Another well-known staging tool is the Edmonton Obesity Staging System (EOSS), which is based on the medical, mental and functional impact of obesity [14]. There are 5 stages that represent increased obesity severity from stage 0 (no apparent risk factors) through stage 1 (subclinical risk factors), stage 2 (presence of established obesity-related complications), stage 3 (end-organ damage) and stage 4 (end-stage disability). The
EOSS recommends the optimal obesity management according to the stage, providing clinical guidance on the need and urgency for achieving weight loss. Additionally, the EOSS is able to predict mortality [16]. In order to shift the focus from BMI and redefine obesity as a complications-centric chronic disease, the American Association of Clinical Endocrinologists and the American College of Endocrinology have proposed Adiposity-Based Chronic Disease (ABCD) as a new term for obesity [17].

\section{Clinical Assessment of the Patient With Obesity}

\section{Medical History}

The medical history comprises presenting symptoms, complications and health risks, weight loss history, lifestyle (nutrition and physical activity), eating behaviours, depression and mood disorders, and chronic psychological stress [7]. The causes for weight gain are complex and multifactorial, ranging from genetic predisposition and individual physiology, through psychological issues, to social and pro-obesogenic environments. The weight history may assist in establishing the underlying causes for weight gain by exploring weight gain onset, weight gain patterns (for instance, changes in clothing sizes are a valuable and easily accessible clue), events that aggravated weight gain, such as pregnancies, decreased physical activity, eating disorders or psychological problems, and previous attempts at weight loss. Moreover, there are several endocrine disturbances that may cause or contribute towards obesity. This includes, but is not limited to, hypothalamic obesity, Cushing's syndrome, hypogonadism, androgen
Table 1 King's Obesity Staging Criteria addresses 12 different domains from A to L. The 12 domains follow an alphabetical order and include airway, BMI, cardiovascular disease, diabetes, economic complications, functional status, gonadal axis, health status (as perceived by the patient) and body image. Additional criteria include gastro-oesophageal junction, kidney disease and liver disease. For each domain, a score of 0 (normal health), 1 (at risk of disease), 2 (established disease) or 3 (advanced disease) is assigned [15]

\begin{tabular}{|c|c|c|c|c|}
\hline & $\begin{array}{l}\text { Stage } 0 \\
\text { 'Normal health' }\end{array}$ & $\begin{array}{l}\text { Stage } 1 \\
\text { 'At risk of disease' }\end{array}$ & $\begin{array}{l}\text { Stage } 2 \\
\text { 'Established disease' }\end{array}$ & $\begin{array}{l}\text { Stage } 3 \\
\text { 'Advanced disease' }\end{array}$ \\
\hline A-airway & Normal & Snoring & Requires CPAP & Cor pulmonale \\
\hline B — body Mass Index & $<35 \mathrm{~kg} / \mathrm{m}^{2}$ & $35-50 \mathrm{~kg} / \mathrm{m}^{2}$ & $50-60 \mathrm{~kg} / \mathrm{m}^{2}$ & $>60 \mathrm{~kg} / \mathrm{m}^{2}$ \\
\hline $\mathrm{C}$ - cardiovascular Risk & $<10 \%$ risk & $10-20 \%$ risk & Heart disease & Heart failure \\
\hline $\mathrm{D}$ _diabetes & Normal & Impaired fasting glycaemia & Type 2 diabetes & Uncontrolled type 2 diabetes \\
\hline $\begin{array}{l}\mathrm{E} \text { - economic } \\
\text { complications }\end{array}$ & Normal & Expensive travel/clothes & $\begin{array}{l}\text { Workplace } \\
\text { discrimination }\end{array}$ & Unemployed due to obesity \\
\hline $\mathrm{F}$-functional & Can manage three flights of stairs & $\begin{array}{l}\text { Manages one or two } \\
\text { flight of stairs }\end{array}$ & $\begin{array}{l}\text { Requires walking aids or } \\
\text { wheel chair }\end{array}$ & House bound \\
\hline $\mathrm{G}$-gonadal & Normal & PCOS & Infertility & Sexual dysfunction \\
\hline $\mathrm{H}-$ health perceived & Normal & Low mood or poor QoL & Depression or poor QoL & Severe depression \\
\hline I-body image & Normal & Dislikes body & Body image dysphoria & Eating disorder \\
\hline
\end{tabular}

$C P A P$ continuous positive airway pressure, $P C O S$ polycystic ovary syndrome, $Q o L$ quality of life 
excess in women, hypopituitarism and genetic syndromes. Although routine screening is not recommended, a high clinical suspicion for these entities is warranted [18•].

In terms of current medication, we liaise with the patient's general practitioner (GP), advising to change any medication that may cause weight gain, most notably sulphonylureas, insulin, antipsychotics and some antidepressants, to agents that are either weight-neutral or which assist with weight loss, if feasible [19]. In the social history, smoking status and alcohol intake, as well as the employment and economic impact of obesity, are evaluated. The family history of obesity and other cardiometabolic diseases should be established.

The patient's current diet and eating behaviour, including sources of excess calories, adequacy of macro and micronutrient intake, meal patterns and the need for modification, are ascertained in conjunction with the dieticians. The physician should also enquire about physical activity and sleep patterns as these may contribute to excessive weight gain [20]. Furthermore, the patient's motivation for change and their expectations for weight loss and health improvement should be explored. There is a need to determine the requirement for expedited bariatric surgery, for example, weight loss, as a prerequisite for urgent surgery, such as knee replacement or renal transplant.

Finally, throughout the assessment, it is imperative that the language used in verbal and written communication is nonjudgmental and respectful, and one where the patient is actively engaged and involved in all the decision-making processes.

\section{Complications Status}

Complications of obesity are frequent and result in significant morbidity, mortality and healthcare costs. The primary role of the obesity physician, both in terms of an individual patient's care and the healthcare system, is to mitigate these effects by ensuring all complications are diagnosed and optimally managed. These complications can be divided into metabolic, mechanical and mental categories.

In patients with known heart disease, the precise pathogenesis should be ascertained: ischaemic heart disease is common and must be managed prior to aggressive attempts at weight loss (e.g. bariatric surgery), but so too are non-ischaemic cardiac pathologies that may be ameliorated by weight loss itself [21].

Patients with T2DM should be reviewed in respect to their current blood glucose-lowering therapies, presence of microand macrovascular complications and glycaemic control by measuring baseline glycated haemoglobin ( $\mathrm{HbAlc})$. Knowledge of the side effect profiles and weight-related effects of diabetes medications enables individualised regimens to be designed which in many circumstances may assist with weight loss. Prior to bariatric surgery, there is a need to optimise glycaemic control to reduce the risk of perioperative complications [22]. Therefore, the HbAlc target is 6.5 to $7 \%$, although a $\mathrm{HbA} 1 \mathrm{c}$ up to $8 \%$ remains acceptable for patients with longstanding T2DM and diabetic complications $[23 \bullet \bullet]$.

Sleep disordered breathing is highly prevalent in patients with complex and severe obesity. Within our population $70 \%$ were diagnosed with OSA, with $40 \%$ requiring peri-operative planning with continuous positive airway pressure (CPAP) therapy [24]. Screening tools include the Epworth Sleepiness Scale, the STOP-Bang (Snoring, Tiredness, Observed apnoea, high blood Pressure, Body mass index, Age, Neck circumference and Gender) and the Berlin questionnaire, though none is highly specific or sensitive [25]. In our centre, regardless of the score, patients who have not been previously diagnosed with OSA undertake an overnight sleep oximetry test. Although, the international consensus is for the use of overnight attended polysomnography, this is recognised as costly and may not be practical [26]. Therefore, our centre has adopted a sleep oximetry test as a cost-effective screening tool. Patients with moderate/severe OSA should adapt to treatment, CPAP, prior to bariatric surgery, due to the risk of postsurgery respiratory failure in patients with untreated OSA [26].

Non-alcoholic fatty liver disease (NAFLD) and its progressive form, non-alcoholic steatohepatitis (NASH), are increasing in prevalence in tandem with the obesity epidemic [27]. Importantly, NASH may progress to cirrhosis and may soon become the leading cause of liver failure [28]. Portal hypertension may affect the patient's suitability for bariatric surgery. The presence of advanced liver fibrosis (F3 or higher histological grade) is predicted by the fibrosis-4 index, thereafter followed by transient elastography, if required [29].

The psychosocial evaluation aims to identify psychological issues that may need to be addressed, such as eating disorders and past or current trauma, which may impact eating patterns and existing or previously unidentified mental health issues. In our service, we routinely use the Hospital Anxiety and Depression Scale (HADS) [30]. Other available tools are the Patient Health Questionnaire (PHQ-9) [31] and Generalised Anxiety Disorder Assessment (GAD-7) [32].

\section{Physical Examination}

The physical examination is directed toward finding the cause of obesity, identifying complications that are already present and defining the pattern of adiposity which inform the risk of future complications. Essential measurements include height, weight, waist circumference and blood pressure. Hip circumference and neck circumference are useful in defining the pattern of adiposity and as a basis for future comparison following weight loss interventions.

The presence and impact of obesity-related complications should be evaluated. Important priorities include seeking signs 
of left- and right-sided heart failure, portal hypertension, insulin resistance and psychiatric disease. In addition, the physician should assess for signs of endocrinopathies as an underlying cause for obesity. These include easy bruising, facial plethora and supraclavicular fullness for Cushing's syndrome, myxedematous features for severe hypothyroidism, and, in women, hirsutism and acne for androgen excess. Acanthosis nigricans, if present, alerts to possible insulin resistance. It is important to note that the clinic should be equipped with appropriate chairs, scales, beds and sphygmomanometer cuffs to suit all patients.

\section{Investigations}

A comprehensive panel of blood tests is requested at the initial assessment comprising a full blood count, liver function, renal function, parathyroid hormone, calcium, 25 hydroxy-vitamin D, ferritin, vitamin B12 and folate [33]. Vitamin A, zinc, copper and selenium should be checked prior to bariatric surgery in patients undergoing malabsorptive procedures such as biliopancreatic diversion/duodenal switch or if deficiency is suspected [33]. It is important to identify such nutritional deficiencies and institute treatment. Baseline screening tests include a thyroid-stimulating hormone level for thyroid dysfunction and a fasting blood glucose/HbA1c for T2DM. A lipid profile, including total cholesterol, HDL cholesterol and triglyceride concentrations, provides a diagnosis of dyslipidaemia. The investigations required are shown in Table 2. Additional investigations may be required if secondary causes of obesity are suspected or for the assessment of complications.

The baseline panel may be performed in primary care, whilst the additional investigations, dependent on clinical assessment, should be completed in secondary care.

Table 2 Recommended biochemical investigations prior to bariatric surgery [33]

Investigations
Full blood count
Ferritin
Folate
Vitamin B12
25 -hydroxyvitamin D
Calcium
Parathyroid hormone
HbA1c and fasting plasma glucose and/or oral glucose tolerance test
Lipid profile
Liver function
Renal function
Vitamin A, zinc, copper and selenium if patient undergoing
malabsorptive procedures or suspected deficiencies

\section{Treatment}

Rather than focusing on BMI targets, the treatment objective is to produce clinically meaningful weight loss, which leads to either prevention or reduction of obesity associated complications that will improve the patient's overall health. It is the physician's responsibility to inform the patient about the different treatment possibilities, the expected health benefits, potential weight loss and possible complications. The management plan should be individualised, addressing the underlying drivers for weight gain.

Lifestyle measures should form the basis to any approach and comprise three fundamental components: diet therapy (reduce energy intake by $500-1000 \mathrm{kcal} /$ day), physical activity (initially, at least $150 \mathrm{~min} /$ week moderate aerobic exercise combined with 1-3 sessions/week resistance exercise) and behavioural change [7]. Although vital, this combined approach is not often, by itself, sufficient for achieving significant weight loss in patients with severe obesity. Therefore, these patients should receive treatment, in addition to lifestyle measures, including pharmacotherapy and consideration of bariatric surgery. If feasible, the patient's participation in clinical trials is encouraged. Regardless of the treatment type, patients should be seen at regular intervals to ensure that they have ongoing support, assess for underlying barriers to successful treatment and discuss further treatment options if necessary. The clinician should select follow-up intervals using their expertise and according to the patient's complications status and current obesity treatment. Ongoing support may be provided by any member of the multidisciplinary team as deemed appropriate. Remote health provision including telephone or video calls, and digital interventions, such as webbased or app-based programmes, meets patient demands for more convenient access to healthcare and have been shown to be as effective as face-to-face interventions in weight management programmes [34].

\section{Diet-Based Approaches}

Weight loss can only be achieved through a persistent energy deficit. Dietary approaches that facilitate reduced energy intake, irrespective of the macronutrient composition, result in weight loss [35]. Recent evidence suggests that low-carbohydrate diets that promote ketosis may be promising in producing clinically significant weight loss and improving T2DM control [36]. However, further investigation is warranted. The Diabetes Remission Clinical Trial (DiRECT) demonstrated that T2DM of less than 6 years duration can be put into remission with a lowcalorie diet [37•]. These approaches are recommended for short periods of time and only with nutritionally complete meal-replacement formulas. 


\section{Pharmacotherapy}

Pharmacotherapy combined with lifestyle modification is a treatment option for patients with a BMI $\geq 30 \mathrm{~kg} / \mathrm{m}^{2}$ or a BMI of 27 to $29.9 \mathrm{~kg} / \mathrm{m}^{2}$ with obesity-related complications [7]. The European Medication Agency has approved the use of orlistat, naltrexone/bupropion sustained-release and liraglutide $3.0 \mathrm{mg}$ in Europe for obesity management. Furthermore, the National Institute for Health and Care Excellence (NICE) has approved the use of liraglutide $3.0 \mathrm{mg}$ in the English and Welsh National Health Service (NHS) for patients with a BMI $\geq 35 \mathrm{~kg} / \mathrm{m}^{2}$, non-diabetic hyperglycaemia, increased cardiovascular risk and referred to a specialist multidisciplinary weight management service [38]. The Food and Drug Administration (FDA) has also approved phentermine/topiramate for use in the United States of America (US) [19]. Lorcaserin has recently been withdrawn from the US market following FDA safety concerns on increased occurrence of cancer in a safety clinical trial [39].

It is the physician's role to consider all the risks and benefits, efficacy, cost and availability of the different pharmacotherapeutic options. The physician should explain these pharmacotherapy options to the patient and initiate treatment where appropriate. In addition, there is a need to monitor for efficacy and adverse events monthly during the first 3 months and 3-monthly thereafter [19]. The medication should be started at a low dose and up-titrated, according to tolerability. If the patient is a non-responder (i.e. does not lose at least $5 \%$ of body weight at 12 weeks), treatment should be discontinued.

Results from the SCALE Diabetes trial with liraglutide show that, when medication is stopped after satisfactory weight loss, weight regain occurs [40]. Therefore, pharmacotherapy for obesity, like other chronic conditions, should be for long-term use. It is noted that, when used alongside behavioural change strategies, pharmacotherapy is associated with more effective weight loss [41]. The greater understanding of obesity's pathophysiology has stirred the development of new anti-obesity drugs. There are several agents in development, including centrally acting agents, gut hormones and incretin targets, and anti-obesity vaccines [42]. In patients with T2DM and obesity, blood glucose-lowering agents such as glucagonlike peptide 1 receptor agonists or sodium-glucose cotransporter 2 inhibitors are preferred second-line treatment options after metformin [43]. In addition to lowering blood glucose and assisting with weight loss, some of these agents have also shown cardiovascular and renal benefits [44].

\section{Endoscopic Options}

The use of endoscopic methods such as intragastric balloons, endoluminal sleeve barrier devices, endoscopic sleeve gastrectomy, duodenal mucosal resurfacing and gastric aspiration devices may be considered in select patients [45], although most of these interventions are not routinely available in NHS practice. Not only are these therapies minimally invasive and potentially associated with greater weight loss than obesity pharmacotherapy but they may also be less expensive and have fewer complications than bariatric surgery [46]. However, long-term outcome data for these procedures are required. Endoscopic interventions may offer an opportunity to bridge high-risk patients to bariatric surgery. A combination of pharmacotherapy and endoscopic procedures may also be considered a possibility for obesity management in the future.

\section{Surgical Options}

Bariatric-metabolic surgery is a treatment option for patients with a BMI $\geq 40 \mathrm{~kg} / \mathrm{m}^{2}$ or for those with a BMI of 35 to 39.9 $\mathrm{kg} / \mathrm{m}^{2}$ and other significant diseases that may be improved with weight loss. Bariatric surgery may also be an option for patients with a BMI $30.0-34.9 \mathrm{~kg} / \mathrm{m}^{2}$ and recently diagnosed T2DM. In order to fulfil the NICE criteria for bariatric surgery, the patient should have failed to achieve or maintain clinically beneficial weight loss by other means and completed a tier 3 service or equivalent programme, be generally fit for anaesthesia and surgery and be committed to the need for long-term follow-up. Moreover, patients whose BMI is greater than $50 \mathrm{~kg} / \mathrm{m}^{2}$ can progress directly to bariatric surgery without attending a tier 3 service [47]. The surgical options available are vertical sleeve gastrectomy (VSG), Roux-en-Y gastric bypass (RYGP), laparoscopic adjustable gastric band (LAGB), biliopancreatic diversion/duodenal switch (BPD/ DS) and one anastomosis gastric bypass/mini gastric bypass (OAGB/MGB). The choice of surgical intervention should be discussed with the bariatric surgeon and take into account the degree of obesity, complications, long-term effects, experience of the surgeon and facilities and equipment available. The bariatric surgical procedure trends have changed. Currently, the use of VSG has increased, whereas the LAGB has declined [48]. The STAMPEDE trial demonstrated that VSG and RYGP were more effective than intensive medical therapy for T2DM in a 5-year follow-up study [49••]. Furthermore, RYGP was superior to VSG in respect to weight loss and use of fewer glucose-lowering medications [49••]. Despite the beneficial impact on several health parameters including mortality [50], the number of bariatric surgical procedures in the United Kingdom (UK) remains low [51].

\section{Management After Bariatric Surgery}

Continued surveillance post-surgery by a multidisciplinary team (MDT) is necessary to promote treatment success and prevent weight regain. The obesity physician's role involves reassessment of obesity-related complications using staging tools (e.g. 
KOSC and EOSS). Furthermore, it is important to review medication which usually requires de-escalation of doses.

Blood pressure should be routinely measured in clinic, and antihypertensives should be reviewed, as it may be necessary to reduce doses. Patients with T2DM can restart metformin the 3rd day after surgery provided renal function is adequate. Thereafter, capillary blood glucose should be closely monitored with a target value of $100-120 \mathrm{mg} / \mathrm{dL}(5.6-6.7 \mathrm{mmol} / \mathrm{L})$ and $180 \mathrm{mg} / \mathrm{dL}(10 \mathrm{mmol} / \mathrm{L})$, before and after meals, respectively [23••]. At discharge, the decision to maintain insulin or other blood glucose-lowering agents is individually based according to the preoperative diabetes regimen, type of procedure and insulin requirements whilst at hospital. If the patient still requires insulin, a reduced dose of basal insulin should be prescribed and the patient advised to taper insulin units according to capillary blood glucose readings to ensure hypoglycaemia does not occur [23••].

The need for CPAP should be reassessed in patients with known OSA in 3 to 6 months post-surgery [23••].

As preexisting mental health issues may remain a concern, ongoing review and psychological support should be provided. It is important to note that the pharmacokinetics and pharmacodynamics of certain medications may be altered due to anatomical changes, and therefore, more frequent monitoring of plasma levels is needed to ensure therapeutic levels. In addition, some medications are prescribed according to weight, and there may be a need to adjust the dose following significant weight loss [52].

In the UK, patients are followed up at the post-operative obesity clinic for 2 years. In our centre, patients are assessed at 3,12 and 24 months post-bariatric surgery. Weight and metabolic changes typically play out over a 1-2-year timeframe post-surgery, and specialist care, provided by a MDT, should continue for complex patients until weight stability is achieved; the 2-year follow-up package recommended by NICE guidelines is thought to be the most cost-effective [47].

\section{Complications of Bariatric Surgery}

Major complications after bariatric surgery are rare; nevertheless, it is important to recognise their presentation and understand their management.

\section{Vomiting, Dysphagia or Severe Abdominal Pain}

In these cases, an urgent onward referral to the bariatric surgeon is mandatory.

Wernicke encephalopathy (WE) is an acute neuropsychiatric syndrome caused by thiamine (vitamin b1) deficiency and characterised by a clinical triad of ataxia, ophthalmoplegia and mental status change. Patients undergoing bariatric surgery are at risk of developing WE, especially within 6 months of surgery [53]. The greatest risk of developing thiamine deficiency occurs with prolonged vomiting, poor dietary intake, rapid weight loss and alcohol abuse [54]. WE is a medical emergency, and the aim of treatment is prompt correction of thiamine deficiency. IV glucose should be avoided [55].

\section{Nutritional Deficiencies}

From a medical perspective, nutritional deficiencies are the most important long-term complication of concern. In order to prevent micronutrient deficiencies, the physician should ensure that vitamins and minerals are adequately replaced and that the patient understands the importance of multivitamin compliance. Our team, in line with British Obesity \& Metabolic Surgery Society (BOMSS) guidelines, recommends the multivitamin and mineral supplementation shown in Table 3 [33]. In follow-up, we request the same blood test panel as used for the preoperative bariatric work-up. Fatsoluble vitamins $\mathrm{A}, \mathrm{E}$ and $\mathrm{K}$, zinc, copper and selenium are tested if clinically pertinent.

\section{Dumping and Post-Prandial Hypoglycaemia}

The physician should screen for early dumping syndrome, which causes gastrointestinal symptoms such as abdominal pain, nausea, diarrhoea and vasomotor symptoms such as tachycardia and perspiration, within $1 \mathrm{~h}$ after eating. This is usually due to rapid loading of the small bowel with highcalorie-dense food, causing a shift of fluid from the intravascular compartment to the intestinal lumen [56]. Patients should be advised to eat smaller and more frequent meals, eat complex carbohydrate and protein-rich foods, and avoid simple sugars.

Late dumping syndrome, currently known as post-prandial hyperinsulinemic hypoglycaemia, typically occurs more than 1 year after surgery, and symptoms manifest 1 to $3 \mathrm{~h}$ postprandially [57]. The diagnosis is based on the Whipple's hypoglycaemia criteria and includes neuroglycopenic symptoms with concomitant low plasma glucose with symptoms relieved by the correction of the hypoglycaemia. Although, it is more extensively recognised post-gastric bypass, and it can also occur after sleeve gastrectomy [58]. The physician should recommend dietary modification and, in more serious cases, medical therapy such as acarbose, diazoxide or octreotide should be considered [59]. Studies suggest that predictors for both conditions include lower BMI and younger age [60].

\section{Weight Regain}

Long-term management of weight loss can be challenging, as physiological responses to weight loss favour weight regain. Weight regain lacks a standardised definition; however, weight regain measured as the percentage of maximum weight lost has shown the strongest association with clinical outcomes [61]. 
Table 3 Recommended multivitamin and mineral supplementation post bariatric surgery [33]

\begin{tabular}{|c|c|}
\hline Vitamins and minerals & Dosage and frequency \\
\hline $\begin{array}{l}\text { Complete multivitamin and } \\
\text { mineral supplement }\end{array}$ & $\begin{array}{l}\text { Once or twice daily. Containing thiamine, iron, selenium, } \\
\text { zinc (at least } 15 \mathrm{mg} \text { ) and copper (at least } 2 \mathrm{mg} \text { ). }\end{array}$ \\
\hline Iron & $\begin{array}{l}\text { Once daily } 200 \mathrm{mg} \text { ferrous sulphate daily, or } \\
\text { Once daily } 210 \mathrm{mg} \text { ferrous fumarate daily, or } \\
\text { Once daily } 300 \mathrm{mg} \text { ferrous gluconate daily } \\
\text { Women who are menstruating should take two tablets daily }\end{array}$ \\
\hline Vitamin B12 & Three monthly intramuscular injection \\
\hline Vitamin D & $\begin{array}{l}\text { Starting regimes of } 2000-4000 \mathrm{IU} \text { per day. Aim to maintain } \\
\text { serum } 25 \mathrm{OHD} \text { levels greater than } 75 \mathrm{nmol} / \mathrm{L} \text {. }\end{array}$ \\
\hline Calcium & $\begin{array}{l}\text { Ensure good dietary calcium intake. Combined calcium and vitamin } \\
\mathrm{D} \text { supplementation should be considered if PTH is raised despite adequate } \\
\text { calcium and } 25 \mathrm{OHD} \text { levels }\end{array}$ \\
\hline Folic acid & $\begin{array}{l}\text { As part of the complete multivitamin and mineral (at least } 400 \mu \mathrm{g} \text { ). Increased } \\
\text { requirements for preconceptual care, pregnancy and lactation. }\end{array}$ \\
\hline Vitamin A, E, K & $\begin{array}{l}\text { As part of the complete multivitamin and mineral supplement } \\
\text { For BPD/DS: } 10,000 \mathrm{IU} \text { vitamin A daily, } 100 \mathrm{IU} \text { vitamin } \mathrm{E} \text { daily, } 300 \mu \mathrm{g} \text { vitamin } \mathrm{K} \text { daily }\end{array}$ \\
\hline
\end{tabular}

Following a laparoscopic adjustable gastric band, only a complete multivitamin and mineral supplement and vitamin $\mathrm{D}$ is required $B P D / D S$ biliopancreatic diversion/duodenal switch, $I U$ international units, $P T H$ parathyroid hormone, 25OHD 25-hydroxyvitamin D

Maintaining long-term weight loss requires adherence to a dietary and physical activity plan. Additionally, continuing antiobesity medication after weight loss has been shown to prevent weight regain [62]. Some studies have demonstrated that liraglutide may assist in weight loss maintenance and improve diabetes control after bariatric surgery [63•].

Preoperative predictive factors for weight regain have been explored and include older age, diabetes and psychiatric disorders, whereas post-operative predictors comprise nutritional non-compliance, hormonal/metabolic imbalance, physical inactivity and psychiatric complications [64]. If there is a postsurgical failure to lose weight or if there is a significant weight regain associated with complications, the patient may be considered for revisional surgery. Due to the higher perioperative complications associated with revisional surgery, this should be undertaken only in centres with extensive experience.

\section{Weight Management Services: The UK Tier Model}

In the UK, weight management services follow a 4-tier model of care: tier 1, universal interventions that include prevention and reinforcement of a healthy lifestyle; tier 2 , community-based lifestyle weight management services; tier 3, specialised weight loss programmes delivered by a clinician-led MDT; and tier 4, complex obesity services that include bariatric surgery [65]. The obesity physician is present at the tier 3 and tier 4 levels.

However, there is a disparity in the current provision of these services across the UK; hence, the need for a national strategy to develop an optimum patient pathway for obesity. Detailed guidance on infrastructure, staffing and referral pathways for weight assessment and management clinics for severe complex obesity in the UK are available [66], and this may be relevant for other international healthcare systems.

Despite bariatric surgery being the most effective treatment for severe obesity, current health systems are resourced to provide surgery for a fraction of such patients. Furthermore, almost $20 \%$ of patients who receive surgery have no, or only one, obesity-related complication [67]. It seems therefore that healthcare systems are not adequately directing resources towards those with the highest need and who will generate the biggest healthcare gains by having surgery. The COVID-19 pandemic has highlighted the need to stratify patients with obesity according to severity and metabolic risk, and for establishing prioritisation systems for bariatric surgery [68].

We advocate a move towards case-finding of those with, or potentially with, complicated obesity in population, with the process led by obesity physicians. This provides an effective means of prioritisation, so that those with the greatest need can be entered onto surgical pathways.

The obesity physician has an important role in ensuring the accurate assessment of complication burden, whilst the allocation of surgery is best decided by a MDT, based on the outcomes of the physician assessment. Direct-to-surgeon referrals, with the physician relegated to a preoperative optimisation role, fail to address the biggest determinant of how much value bariatric surgery can yield at a system level. In centres where bariatric surgery units are not present, the team may refer into a surgical centre, once the clinical assessment and MDT discussion is complete. In less resourced countries, 
assessments made by the obesity physician could be approximated using questionnaire-based assessments of symptoms (e.g. scoring for the likelihood of sleep apnoea). But the majority of such tools are either not validated or perform only moderately at best and can therefore not replace the role of the obesity physician. Although there are no studies which have addressed a cost-analysis of the bariatric physician, physicians in this role provide early detection and intervention with regard to remediable obesity-related complications, as well as optimising the resource allocation in a resource-scarce environment, which is an indisputable asset.

A summary of the bariatric-metabolic physician tasks in the assessment and management of patients living with obesity is shown in Fig. 1.

\section{Our Experience}

The obesity and bariatric service at our centre is part of the Diabetes and Endocrinology department in a teaching hospital in Central London. The surgical assessment and bariatric surgery occur in another centre. The regional service is provided jointly by these two centres, that are both parts of an Academic Health Sciences Centre. Around 400 new patients are referred annually to the service, and about half are prepared for bariatric surgery. There is a close relationship with the local tier 3 programme, where a significant number of patients take part in a low-calorie diet programme for weight loss.

At our centre, all patients attend a bariatric group education session prior to the Medical Obesity Clinic. This group session discusses lifestyle, pharmacotherapy, endoscopic interventions and metabolic surgical options, the different types of procedures available and what to expect from the pre- and post-operative periods and community and specialist services.
All patients within the bariatric surgical pathway attend a psycho-educational group session, which provides information on relevant psychological, emotional and lifestyle changes or processes. This helps them make an informed decision on their treatment. In addition, a psychological screening triage, based on questionnaires, is conducted in order to help determine the patient's needs or difficulties in this area. According to the outcomes, some patients are assessed more comprehensively by the psychologist in a 1:1 clinic, or take part in a disorderedeating group facilitated by the team's psychologist.

In the Medical Obesity Clinic, patients are assessed by an obesity physician, a specialist dietitian and a diabetes specialist nurse for patients with T2DM. At the post-clinic meeting, healthcare professionals work together to formalise a plan for each patient, for instance, agreeing on a referral to the psychiatric team, optimisation of T2DM or need for further cardiovascular investigations.

Once the medical workup is complete, the decision to proceed to bariatric surgery is made by a MDT which includes the obesity physicians, bariatric surgeons, dietitians, psychologists, gastroenterologists, respiratory physicians and anaesthetics. Complex patients will require multiple MDT discussions. After the MDT meeting, the patient is assessed by the bariatric surgeon. The bariatric coordinator plays an important role in bringing together members of the MDT, collating the relevant medical information related to each patient and gathering post-operative data for the National Bariatric Surgery Register.

Thereafter, dietetic, medical and surgical input is provided up to 2 years post-bariatric surgery. The patient's care is then returned to Primary Care with a comprehensive discharge summary clarifying the importance of lifelong follow-up and the need for annual nutritional monitoring and appropriate supplementation.
Fig. 1 The role of the bariatricmetabolic physician in managing clinically severe obesity. The bariatric-metabolic physician is responsible for providing comprehensive health care to patients living with clinically severe obesity including, but not limited to, exclusion of secondary causes, anthropometric measures, complications screening, eating disorder screening, assessment of motivation, advice on weight loss pharmacotherapy, T2DM optimisation and management after weight-loss interventions

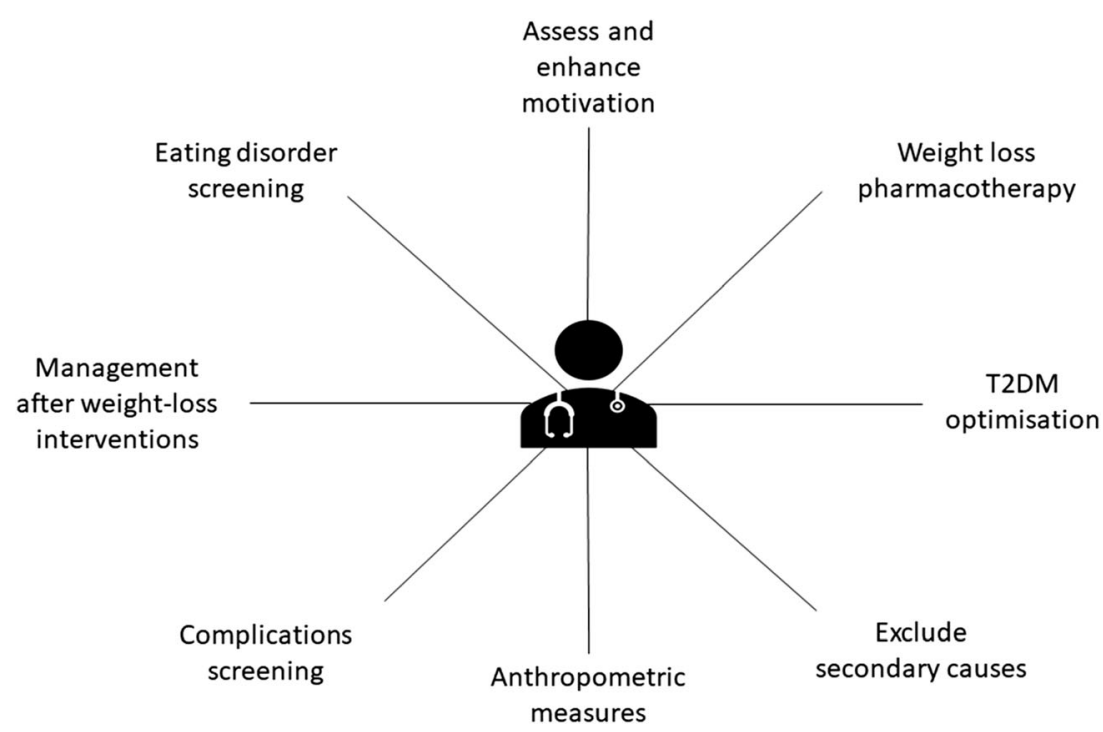




\section{Conclusion}

The bariatric-metabolic physician has an important role in the comprehensive assessment of a patient with obesity. It is the physician's task to determine the degree and severity of obesity in order to establish the individual's health risk and provide a basis for decision-making. Furthermore, the obesity physician should evaluate the eligibility and medical suitability for weight loss interventions and advise on medical management. In a more global perspective, it is the physician's responsibility to advocate for policies that recognise obesity as a chronic disease and reduce weight stigma.

Data Availability Not applicable

Code Availability Not applicable

\section{Declataions}

Ethics Approval Not applicable

\section{Consent to Participate Not applicable}

Consent for Publication Not applicable

Human and Animal Rights and Informed Consent This article does not contain any studies with human or animal subjects performed by any of the authors.

Conflict of Interest Author Barbara McGowan reports grants and personal fees from Novonordisk, and personal fees for educational work from, Jansen, Lilly, BI, Napp, Novonordisk, outside the submitted work; Shareholder in Reset Health Clinics

\section{References}

Papers of particular interest, published recently, have been highlighted as:

- Of importance

• Of major importance

1. Organization World Health. Obesity and overweight. In: Fact Sheets. 2018. https://www.who.int/en/news-room/fact-sheets/ detail/obesity-and-overweight. Accessed 5 June 2020.

2. Collaborators GBD 2015 O, Afshin A, Forouzanfar MH, Reitsma MB, Sur P, Estep K, et al. Health effects of overweight and obesity in 195 Countries over 25 Years. N Engl J Med. 2017;377(1):13-27. https://doi.org/10.1056/NEJMoa1614362.

3. Hales CM, Fryar CD, Carroll MD, Freedman DS, Ogden CL. Trends in obesity and severe obesity prevalence in US youth and adults by sex and age, 2007-2008 to 2015-2016. JAMA. 2018;319(16):1723-5. https://doi.org/10.1001/jama.2018.3060.

4. Ng M, Fleming T, Robinson M, Thomson B, Graetz N, Margono C, et al. Global, regional, and national prevalence of overweight and obesity in children and adults during 1980-2013: a systematic analysis for the Global Burden of Disease Study 2013. Lancet.
2014;384(9945):766-81. https://doi.org/10.1016/S0140-6736(14) 60460-8.

5. Kinlen D, Cody D, O'Shea D. Complications of obesity. QJM An Int $J$ Med. 2017;111(7):437-43. https://doi.org/10.1093/qjmed/ hcx 152.

6. Bray GA, Kim KK, Wilding JPH. Obesity: a chronic relapsing progressive disease process. A position statement of the World Obesity Federation. Obes Rev. 2017;18(7):715-23. https://doi.org/ 10.1111/obr.12551 This article elucidates why obesity should be considered a chronic disease. It explains how obesity fits the epidemiological model of a disease process.

7. Yumuk V, Tsigos C, Fried M, Schindler K, Busetto L, Micic D, et al. European guidelines for obesity management in adults. Obes Facts. 2015;8(6):402-24. https://doi.org/10.1159/000442721.

8.• Mechanick JI, Apovian C, Brethauer S, Garvey WT, Joffe AM, Kim J, et al. Clinical practice guidelines for the perioperative nutrition, metabolic, and nonsurgical support of patients undergoing bariatric procedures - 2019. Surg Obes Relat Dis. 2019;16:175247. https://doi.org/10.1016/j.soard.2019.10.025.

9. Acosta A, Streett S, Kroh MD, Cheskin LJ, Saunders KH, Kurian $\mathrm{M}$, et al. White paper AGA: POWER - practice guide on obesity and weight management, education, and resources. Clin Gastroenterol Hepatol. 2017;15(5):631-649.e10. https://doi.org/ 10.1016/j.cgh.2016.10.023.

10. Wharton S, Lau DCW, Vallis M, Sharma AM, Biertho L, Campbell-Scherer D, et al. Obesity in adults: a clinical practice guideline. CMAJ. 2020;192(31):E875-91. https://doi.org/10. 1503/cmaj.191707.

11. Cornier M-A, Despres J-P, Davis N, Grossniklaus DA, Klein S, Lamarche B, et al. Assessing adiposity: a scientific statement from the American Heart Association. Circulation. 2011;124(18):19962019. https://doi.org/10.1161/CIR.0b013e318233bc6a.

12. Ashwell M, Gunn P, Gibson S. Waist-to-height ratio is a better screening tool than waist circumference and BMI for adult cardiometabolic risk factors: systematic review and meta-analysis. Obes Rev. 2012;13(3):275-86. https://doi.org/10.1111/j.1467-789X. 2011.00952.x.

13. Lemos T, Gallagher D. Current body composition measurement techniques. Curr Opin Endocrinol Diabetes Obes. 2017;24(5): 310-4. https://doi.org/10.1097/MED.0000000000000360.

14. Sharma AM, Kushner RF. A proposed clinical staging system for obesity. Int J Obes (Lond). 2009;33(3):289-95. https://doi.org/10. 1038/ijo.2009.2.

15. Aasheim ET, Aylwin SJB, Radhakrishnan ST, Sood AS, Jovanovic A, Olbers T, et al. Assessment of obesity beyond body mass index to determine benefit of treatment. Clin Obes. 2011;1(2-3):77-84. https://doi.org/10.1111/j.1758-8111.2011.00017.x.

16. Padwal RS, Pajewski NM, Allison DB, Sharma AM. Using the Edmonton obesity staging system to predict mortality in a population-representative cohort of people with overweight and obesity. CMAJ. 2011;183(14):1059-66. https://doi.org/10.1503/ cmaj.110387.

17. Mechanick JI, Hurley DL, Garvey WT. Adiposity-based chronic disease as a new diagnostic term: The American Association Of Clinical Endocrinologists And American College of Endocrinology Position Statement. Endocr Pract. 2017;23(3): 372-8. https://doi.org/10.4158/EP161688.PS.

18. Pasquali R, Casanueva F, Haluzik M, van Hulsteijn L, Ledoux S, Monteiro MP, et al. European Society of Endocrinology Clinical Practice Guideline: endocrine work-up in obesity. Eur $J$ Endocrinol. 2020;182(1):G1-G32. https://doi.org/10.1530/EJE19-0893 A recent clinical practice guideline from the European Society of Endocrinology. It recommends screening all patients with obesity for thyroid dysfunction. However, advises against routine screening for hypercortisolism and gonadal dysfunction. 
19. Apovian CM, Aronne LJ, Bessesen DH, McDonnell ME, Murad MH, Pagotto U, et al. Pharmacological management of obesity: an endocrine Society clinical practice guideline. J Clin Endocrinol Metab. 2015;100(2):342-62. https://doi.org/10.1210/jc.2014-3415.

20. Van der Valk ES, Van den Akker ELT, Savas M, Kleinendorst L, Visser JA, Van Haelst MM, et al. A comprehensive diagnostic approach to detect underlying causes of obesity in adults. Obes Rev. 2019;20(6):795-804. https://doi.org/10.1111/obr.12836.

21. Kuno T, Tanimoto E, Morita S, Shimada YJ. Effects of bariatric surgery on cardiovascular disease: a concise update of recent advances. Front Cardiovasc Med. 2019;6:94. https://doi.org/10.3389/ fcrm.2019.00094.

22. Perna M, Romagnuolo J, Morgan K, Byrne TK, Baker M. Preoperative hemoglobin A1c and postoperative glucose control in outcomes after gastric bypass for obesity. Surg Obes Relat Dis. 2012;8(6):685-90. https://doi.org/10.1016/j.soard.2011.08.002.

23.• Busetto L, Dicker D, Azran C, Batterham RL, Farpour-Lambert N, Fried M, et al. Practical recommendations of the obesity management task force of the European Association for the study of obesity for the post-bariatric surgery medical management. Obes Facts. 2017;10(6):597-632. https://doi.org/10.1159/000481825. These recommendations by the European Association for the Study of Obesity summarise the elementary notions necessary to provide appropriate and effective medical care post-bariatric surgery. This includes information on nutrition, management of complications, psychological aspects, pharmacotherapy and pregnancy after bariatric surgery.

24. Meurgey JH, Brown R, Woroszyl-Chrusciel A, Steier J. Perioperative treatment of sleep-disordered breathing and outcomes in bariatric patients. J Thorac Dis. 2018;10(3):S144-52. https://doi. org/10.21037/jtd.2017.10.11.

25. Kapur VK, Auckley DH, Chowdhuri S, Kuhlmann DC, Mehra R, Ramar K, et al. Clinical practice guideline for diagnostic testing for adult obstructive sleep apnea: an American Academy of Sleep Medicine Clinical Practice Guideline. J Clin Sleep Med. 2017;13(3):479-504. https://doi.org/10.5664/jcsm.6506.

26. De Raaff CAL, Gorter-Stam MAW, de Vries N, Sinha AC, Jaap Bonjer H, Chung F, et al. Perioperative management of obstructive sleep apnea in bariatric surgery: a consensus guideline. Surg Obes Relat Dis. 2017;13(7):1095-109. https://doi.org/10.1016/j.soard. 2017.03.022.

27. Sayiner M, Koenig A, Henry L, Younossi ZM. Epidemiology of nonalcoholic fatty liver disease and nonalcoholic steatohepatitis in the United States and the rest of the world. Clin Liver Dis. 2016;20(2):205-14. https://doi.org/10.1016/j.cld.2015.10.001.

28. Wong RJ, Aguilar M, Cheung R, Perumpail RB, Harrison SA, Younossi ZM, et al. Nonalcoholic steatohepatitis is the second leading etiology of liver disease among adults awaiting liver transplantation in the United States. Gastroenterology. 2015;148(3): 547-55. https://doi.org/10.1053/j.gastro.2014.11.039.

29. Castera L, Friedrich-Rust M, Loomba R. Noninvasive assessment of liver disease in patients with nonalcoholic fatty liver disease. Gastroenterology. 2019:1-19. https://doi.org/10.1053/j.gastro. 2018.12.036.

30. Zigmond AS, Snaith RP. The hospital anxiety and depression scale. Acta Psychiatr Scand. 1983;67(6):361-70. https://doi.org/10.1111/ j.1600-0447.1983.tb09716.x.

31. Spitzer RL, Kroenke K, Williams JB. Validation and utility of a self-report version of PRIME-MD: the PHQ primary care study. Primary care evaluation of mental disorders. Patient health questionnaire. JAMA. 1999;282(18):1737-44. https://doi.org/10.1001/ jama.282.18.1737.

32. Spitzer RL, Kroenke K, Williams JBW, Löwe B. A brief measure for assessing generalized anxiety disorder: the GAD-7. Arch Intern Med. 2006;166(10):1092-7. https://doi.org/10.1001/archinte.166. 10.1092 .
33. O'Kane M, Parretti HM, Pinkney J, Welbourn R, Hughes CA, Mok $\mathrm{K}$, et al. British Obesity and Metabolic Surgery Society Guidelines on perioperative and postoperative biochemical monitoring and micronutrient replacement for patients undergoing bariatric surgery2020 update. Obes Rev. 2020;21(11):1-23. https://doi.org/10.1111/ obr.13087.

34. Befort CA, Vanwormer JJ, Desouza C, Ellerbecket EF, Gajewski B, Kimminau KS, et al. Effect of behavioral therapy with in-clinic or telephone group visits vs in-clinic individual visits on weight loss among patients with obesity in rural clinical practice: a randomized clinical trial. JAMA - JAm Med Assoc. 2021;325(4):363-72. https:// doi.org/10.1001/jama.2020.25855.

35. Ebbeling CB, Leidig MM, Feldman HA, Lovesky MM, Ludwig DS. Effects of a low-glycemic load vs low-fat diet in obese young adults: a randomized trial. JAMA. 2007;297(19):2092-102. https:// doi.org/10.1001/jama.297.19.2092.

36. Ludwig DS. The ketogenic diet: evidence for optimism but highquality research needed. $J$ Nutr. December. 2019;150:1354-9. https://doi.org/10.1093/jn/nxz308.

37. Lean MEJ, Leslie WS, Barnes AC, Brosnahan N, Thom G, McCombie L, et al. Durability of a primary care-led weight-management intervention for remission of type 2 diabetes: 2-year results of the DiRECT open-label, cluster-randomised trial. Lancet Diabetes Endocrinol. 2019;7(5):344-55. https://doi.org/10.1016/ S2213-8587(19)30068-3. The DiRECT trial evaluated remission of type 2 diabetes following an intensive programme for weight loss (intervention) versus best-practice care (control). The intervention consisted of a total diet replacement (825-853 kcal per day for 12-20 weeks), gradual food reintroduction and structured support for weight maintenance. At 24 months, $36 \%$ of the intervention participants had remission of diabetes compared to $3 \%$ of the control participants.

38. National Institute for Health and Care Excellence. Liraglutide for managing overweight and obesity. 2020. www.nice.org.uk/ guidance/ta664. Accessed 25 Jan 2021.

39. Mahase E. Weight loss pill praised as "holy grail" is withdrawn from US market over cancer link. BMJ. 2020;368:m705. https:// doi.org/10.1136/bmj.m705.

40. Davies MJ, Bergenstal R, Bode B, Kushner R, Lewin A, Skjøth $\mathrm{TV}$, et al. Efficacy of liraglutide for weight loss among patients with type 2 diabetes: the SCALE diabetes randomized clinical trial. JAMA - J Am Med Assoc. 2015;314(7):687-99. https://doi.org/10. 1001/jama.2015.9676.

41. Wadden TA, Walsh OA, Berkowitz RI, Chao AM, Alamuddin N, Gruber K, et al. Intensive behavioral therapy for obesity combined with liraglutide $3.0 \mathrm{mg}$ : a randomized controlled trial. Obesity (Silver Spring). 2019;27(1):75-86. https://doi.org/10.1002/oby. 22359.

42. Srivastava G, Apovian C. Future pharmacotherapy for obesity : new anti-obesity drugs on the horizon. Curr Obes Rep. 2018;7: 147-61. https://doi.org/10.1007/s13679-018-0300-4.

43. Davies MJ, D'Alessio DA, Fradkin J, Kernan WN, Mathieu C, Mingrone G, et al. Management of Hyperglycemia in Type 2 Diabetes, 2018. A consensus report by the American Diabetes Association (ADA) and the European Association for the Study of Diabetes (EASD). Diabetes Care. 2018;41(12):2669-701. https://doi.org/10.2337/dci18-0033.

44. Kaul S. Mitigating cardiovascular risk in type 2 diabetes with antidiabetes drugs: a review of principal cardiovascular outcome results of EMPA-REG OUTCOME, LEADER, and SUSTAIN-6 Trials. Diabetes Care. 2017;40(7):821-31. https://doi.org/10.2337/ dc17-0291.

45. Davis M, Kroh M. Novel endoscopic and surgical techniques for treatment of morbid obesity: a glimpse into the future. Surg Clin 
North Am. 2016;96(4):857-73. https://doi.org/10.1016/j.suc.2016. 03.005 .

46. Saunders KH, Igel LI, Saumoy M, Sharaiha RZ, Aronne LJ, Saunders KH. Devices and endoscopic bariatric therapies for obesity. Curr Obes Rep. 2018;7:162-71.

47. National Institute for Health and Care Excellence. Obesity: identification, assessment and management. 2014. https://www.nice.org. uk/guidance/cg189. Accessed 6 Jan 2021.

48. Lo Menzo E, Szomstein S, Rosenthal R. Update on treatment of morbid obesity with adjustable gastric banding. Surg Clin North Am. 2016;96(4):795-813. https://doi.org/10.1016/j.suc.2016.03. 010 .

49.• Schauer PR, Bhatt DL, Kirwan JP, Wolski K, Aminian A, Brethauer SA. Bariatric surgery versus intensive medical therapy for diabetes - 5-year outcomes. $N$ Engl J Med. 2017;376(7):64151. https://doi.org/10.1056/NEJMoa1600869. This trial included 150 patients with type 2 diabetes who were assigned to bariatric surgery (Roux-en-Y gastric bypass or sleeve gastrectomy) and intensive medical therapy or exclusively intensive medical therapy. After 5 years, patients who underwent bariatric surgery had a greater reduction in HbA1c, body weight, cholesterol levels and use of insulin. These results demonstrated that bariatric surgery and intensive medical therapy was more effective than intensive medical therapy alone in patients with type 2 diabetes.

50. Singh P, Subramanian A, Adderley N, Gokhale K, Singhal R, Bellary S, et al. Impact of bariatric surgery on cardiovascular outcomes and mortality: a population-based cohort study. Br J Surg. 2020. https://doi.org/10.1002/bjs.11433.

51. Booth HP, Khan O, Fildes A, Prevost AT, Reddy M, Charlton J, et al. Changing epidemiology of bariatric surgery in the UK: cohort study using primary care electronic health records. Obes Surg. 2016;26(8):1900-5. https://doi.org/10.1007/s11695-015-2032-9.

52. Sarker A, Meek CL, Park A. Biochemical consequences of bariatric surgery for extreme clinical obesity. Ann Clin Biochem. 2016;53(Pt 1):21-31. https://doi.org/10.1177/0004563215588116.

53. Oudman E, Wijnia JW, van Dam M, Biter LU, Postma A. Preventing wernicke encephalopathy after bariatric surgery. Obes Surg. 2018;28(7):2060-8. https://doi.org/10.1007/s11695-0183262-4.

54. Aasheim ET. Wernicke encephalopathy after bariatric surgery: a systematic review. Ann Surg. 2008;248(5):714-20. https://doi.org/ 10.1097/SLA.0b013e3181884308.

55. Galvin R, Bråthen G, Ivashynka A, Hillbom M, Tanasescu R, Leone MA. EFNS guidelines for diagnosis, therapy and prevention of Wernicke encephalopathy. Eur J Neurol. 2010;17(12):1408-18. https://doi.org/10.1111/j.1468-1331.2010.03153.x.

56. Van Beek AP, Emous M, Laville M, Tack J. Dumping syndrome after esophageal, gastric or bariatric surgery: pathophysiology, diagnosis, and management. Obes Rev. 2017;18(1):68-85. https:// doi.org/10.1111/obr.12467.

57. Eisenberg D, Azagury DE, Ghiassi S, Grover BT, Kim JJ. ASMBS position statement on postprandial hyperinsulinemic hypoglycemia after bariatric surgery. Surg Obes Relat Dis. 2017;13(3):371-8. https://doi.org/10.1016/j.soard.2016.12.005.

58. Brix JM, Kopp H-P, Höllerl F, Schernthaner GH, Ludvik B, Schernthaner G. Frequency of hypoglycaemia after different bariatric surgical procedures. Obes Facts. 2019;12(4):397-406. https://doi.org/10.1159/000493735.

59. Salehi M, Vella A, McLaughlin T, Patti ME. Hypoglycemia after gastric bypass surgery: current concepts and controversies. J Clin Endocrinol Metab. 2018;103(8):2815-26. https://doi.org/10.1210/ jc.2018-00528.

60. Nielsen JB, Pedersen AM, Gribsholt SB, Svensson E, Richelsen B. Prevalence, severity, and predictors of symptoms of dumping and hypoglycemia after Roux-en-Y gastric bypass. Surg Obes Relat Dis. 2016;12(8):1562-8. https://doi.org/10.1016/j.soard.2016.04. 017.

61. King WC, Hinerman AS, Belle SH, Wahed AS, Courcoulas AP. Comparison of the performance of common measures of weight regain after bariatric surgery for association with clinical outcomes. JAMA. 2018;320(15):1560-9. https://doi.org/10.1001/jama.2018. 14433.

62. James WPT, Astrup A, Finer N, Hilsted J, Kopelman P, Rössner S, et al. Effect of sibutramine on weight maintenance after weight loss : a randomised trial. Lancet. 2000;356:2119-25.

63. Miras AD, Pérez-Pevida B, Aldhwayan M, , Kamocka A, McGlone ER, Al-Najim W, et al. Adjunctive liraglutide treatment in patients with persistent or recurrent type 2 diabetes after metabolic surgery (GRAVITAS): a randomised, double-blind, placebo-controlled trial. Lancet Diabetes Endocrinol. 2019;7(7):549-559. https://doi.org/ 10.1016/S2213-8587(19)30157-3. GRAVITAS was a randomised double-blind, placebo-controlled trial that demonstrated the benefit of liraglutide post-bariatric surgery in patients with T2DM. The treatment with liraglutide was associated with a difference of $-13.3 \mathrm{mmol} / \mathrm{mol}$ in $\mathrm{HbA1c}$ compared with placebo at 26 weeks.

64. Shukla AP, He D, Saunders KH, Andrew C, Aronne LJ. Current concepts in management of weight regain following bariatric surgery. Expert Rev Endocrinol Metab. 2018;13(2):67-76. https://doi. org/10.1080/17446651.2018.1447922.

65. Capehorn MS, Haslam DW, Welbourn R. Obesity treatment in the UK health system. Curr Obes Rep. 2016;5:320-6. https://doi.org/ 10.1007/s13679-016-0221-z.

66. Welbourn R, Hopkins J, Dixon JB, Finer N, Hughes C, Viner R, et al. Commissioning guidance for weight assessment and management in adults and children with severe complex obesity. Obes Rev. 2018;19(1):14-27. https://doi.org/10.1111/obr.12601.

67. Welbourn R, Small P, Finlay I, Sareela A, Somers S, Mahawar K et al. In: The United Kingdom National Bariatric Surgery Registry Second Registry Report 2014 on Behalf of the NBSR Data Committee The UK National Bariatric Surgery Registry Second Registry Report 2014. 2014. http://www.bomss.org.uk/wpcontent/ uploads/2018/11/Extract_from_the_NBSR_2014_Report-2.pdf. Accessed June 5, 2020.

68. Rubino F, Cohen RV, Mingrone G, le Roux CW, Mechanick JI, Arterburn DE, et al. Bariatric and metabolic surgery during and after the COVID-19 pandemic: DSS recommendations for management of surgical candidates and postoperative patients and prioritisation of access to surgery. Lancet Diabetes Endocrinol. 2020;8(7):640-8. https://doi.org/10.1016/S2213-8587(20)30157-1.

Publisher's Note Springer Nature remains neutral with regard to jurisdictional claims in published maps and institutional affiliations. 